\title{
MRC attacks government proposal to sell off research institutes
}

London. Tensions over the fate of Britain's five research councils broke into the open last week when the head of one, the Medical Research Council, publicly criticized a proposal that the council should sell off its research units and institutes, and restrict itself to distributing research funds. The proposal includes selling such bodies as the MRC's Laboratory of Molecular Biology (LMB) in Cambridge and the National Institute for Medical Research in Mill Hill.

Dai Rees, the secretary to the council, called the idea a "disaster" and said that research institutes are "at the heart of the MRC's strategy". Privatizing the institutes would encourage them to focus on the shortterm needs of the market rather than the long-term needs of society, he said, a change that was "deeply and fundamentally misguided".

The proposals by the Advisory Committee on Science and Technology (ACOST), if adopted, would represent one of the biggest shifts in the MRC's 80-year history and could mark the end of the council in its present form. Although the directors of many of the research institutes would welcome greater flexibility in the way they operate, they do not want to sever direct links with the MRC.

ACOST's proposals are contained in a report drawn up by a subcommittee headed by Sir Robin Nicholson, a science adviser to the former prime minister, Margaret Thatcher. They were put together at the request of William Waldegrave, the Chancellor of the Duchy of Lancaster, whose white paper (policy document) on the reorganization of British science is due early next year.

One proposal that has attracted controversy is to replace the five research councils with two funding bodies. One, known as the Council for the Advancement of Scientific Knowledge (CASK), would assume responsibility for 'curiosity-driven' research; the other, a Council for Mission-Oriented Research (COMR), would handle all research linked to clear social objectives.

The second proposal is to privatize almost all publicly owned laboratories, including those currently run by the research councils. They would either be sold off to companies or universities, or encouraged to become independent contractresearch organizations.

ACOST admits that special steps would be needed to maintain the quality of research carried out in the privatized institutes and that certain functions should be kept in the public domain. Councils such as the MRC would become purely funding agencies, operating as "programme boards" of the new COMR unless they chose to give up any policy-making role and become merely managers of research institutes.

Rees believes that the ACOST proposals run counter to the MRC's own experience. Close contact between basic and clinical research is essential at all levels of research management, he says, citing as an example monoclonal antibodies, which were discovered in the mid-1970s in the MRC's Cambridge laboratories and have since generated a world-wide market valued at $£ 200$ million a year.

Rees also denies that the so-called "protected access" to funding bodies enjoyed by its research institutes has lessened scientific quality. He points out that the MRC's recent decision to close a number of its institutes most recently being its Epidemiology Unit in South Wales - demonstrates that scientific quality remains essential for continued funding.

Aaron Klug, director of the Cambridge laboratory, is equally critical of the recommendations in the ACOST report, saying that "privatization would not do us any good at all". He calls the proposal "a totally retrograde step, because it sets up a false divide between the so-called 'purchasers'

\section{Politics alleged in Indian fraud}

New Delhi. Political interference in investigations of scientific fraud is once again at the centre of a storm in the university town of Chandigarh, northern India. The latest controversy involves Chandigarh's Postgraduate Institute for Medical Research, where the institute's ethics committee has upheld allegations of wrongdoing against one of its staff, dermatologist Bhusnan Kumar. But whereas Kumar is being allowed to remain, the head of his department, Surrinder Kaur, who brought the fraud to light, has resigned and is leaving the institute.

At issue is a paper coauthored by Kumar in the Indian Journal of Dermatology, Venereology and Leprology claiming that the herpes zoster virus had been cultured in egg yolk. Kaur doubted the claim and alleged that the cultures "were not even attempted" and that the data had been fabricated. A nine-member ethics committee reached the same conclusion after a six-month investigation, stating that "the scientific data reported [were] not based on facts". Kumar confessed to the editor of the journal that "the culture results reported cannot be substantiated" and that and 'providers' of research".

Nicholson says that fears of what might happen to research institutes such as the LMB under the ACOST proposals are being exaggerated. "We do not want to destroy the long-term relationship between a research council and an institute and have suggested that this relationship be maintained through long-term rolling contracts", he says. "In particular, ACOST does not think there is anything wrong with the LMB. But we do think that there are things wrong with some of the other research institutes, and can trace these back to their ownership by government departments."

It is not known how much support the proposals have within ACOST. At least two committee members, Sir Michael Atiyah, president of the Royal Society, and Sir David Phillips, the chairman of the Advisory Board for the Research Councils, have publicly expressed their disagreement with some of its conclusions. At the same time, ACOST's conclusion that research institutes should be sold off and operated as private agencies is in line with government policy that has already, for example, been applied to the former United Kingdom Atomic Energy Authority.

David Dickson

\section{he felt sorry for the "glaring error".}

Nonetheless, the institute's governing body has decided against sacking Kumar, saying that he has apologized for the "lapse" and citing his potential as a researcher. Kumar is also a relative of an influential politician who is a member of the governing body. Kaur says that the decision "was an administrative whitewash" and that she quit to focus attention on "blatant political interference in academic affairs". She has asked India's health minister, the chairman of the governing body, to review the case.

The new furore is an echo of similar events at the Panjab University, also in Chandigarh, where palaeontologist Vishwa J. Gupta has clung to his position despite a massive amount of evidence implicating him in the falsification of fossil records in the Himalayas (see Nature $355,579 ; 1992)$. Observers say that the two cases demonstrate the erosion of ethical and academic values at Chandigarh and the futility of exposing misconduct when those accused have powerful political friends.

K.S. Jayaraman 